\title{
Fluoride Determination in Carbon Nanotubes by Ion Selective Electrode
}

\author{
Fabiane G. Antes, Juliana S. F. Pereira, Laurien C. Spadoa, Edson I. Muller, \\ Erico M. M. Flores and Valderi L. Dressler*
}

Departamento de Química, Universidade Federal de Santa Maria, 97105-900 Santa Maria-RS, Brazil

\begin{abstract}
A determinação de fluoreto por eletrodo íon seletivo (ISE) em nanotubos de carbono (CNTs) é proposta após a decomposição por piroidrólise. Até $1 \mathrm{~g}$ de amostra pode ser decomposta, obtendo-se assim baixos limites de detecção $\left(1,5 \mu \mathrm{g} \mathrm{g}^{-1}\right)$, boa precisão (RSD $<5 \%$ ) e exatidão (concordância maior do que $95 \%$ com os valores dos materiais de referencia certificados (CRMs) e combustão iniciada por microondas (MIC)). O fluoreto é absorvido em água e a solução resultante pode ser analisada diretamente por ISE. A pirohidrólise é simples de ser executada e não requer instrumentação sofisticada, sendo bastante atrativa para controle de fluoreto em NTCs em análises de rotina.
\end{abstract}

Fluoride determination by ion selective electrode (ISE) in carbon nanotubes (CNTs) is proposed after pyrohydrolysis decomposition. Up to $1 \mathrm{~g}$ of CNTs could be decomposed improving the limit of detection $\left(1.5 \mu \mathrm{g} \mathrm{g}^{-1}\right)$, precision (RSD < 5\%) and accuracy (agreement higher than 95\% with values of certified reference materials (CRMs) and microwave-induced combustion (MIC)). Fluoride could be absorbed in water and the resulting solution can be analyzed by ISE. Pyrohydrolysis is easy to be performed and does not require any sophisticated instrumentation, which is attractive for routine fluoride control in CNTs.

Keywords: carbon nanotubes, fluoride, ion selective electrode, pyrohydrolysis sample preparation

\section{Introduction}

Nowadays, carbon nanotubes (CNTs) are considered a promising material for several nanotechnological applications (mainly in science and medicine) due to their extraordinary electronic, mechanical and structural properties. ${ }^{1-5}$ The properties of CNTs could be chemically modified by addition of halogens, as fluorine. ${ }^{6-9}$ Some authors have reported that the functionalization of CNTs with fluorine significantly changes their electrical, mechanical and optical properties. ${ }^{8}$ In this sense, the determination of $\mathrm{F}$ in CNT is an important task in order to evaluate the performance of this material for many applications. However, there is a lack of analytical procedures suitable for CNT analysis, especially related to $\mathrm{F}$ determination. Some works have been published concerning CNT analysis, but they are generally devoted to structural characterization, purity evaluation, metals determination, among others. ${ }^{10-14}$ Current procedures recommended for CNT analysis are related to microwave-

*e-mail: valdres@quimica.ufsm.br assisted acid digestion or dry ashing. ${ }^{10,11}$ However, these procedures used for sample digestion are not suitable for further halogens due to the low sample mass that could be digested or the low decomposition efficiency. ${ }^{10,13}$ Additionally, some drawbacks are related to analyte losses during sample treatment, even using closed vessels. ${ }^{15}$

Recently, a method was proposed for halogen determination in CNTs using microwave-induced combustion (MIC) for sample decomposition and inductively coupled plasma mass spectrometry (ICPMS), ion chromatography (IC) and also ion selective electrode (ISE) for analyte measurement. ${ }^{16}$ It was possible to digest up to $500 \mathrm{mg}$ of CNT samples and halogens were quantitatively absorbed in diluted alkaline solutions. However, despite the good performance of MIC for CNT digestion, it was reported that fluoride could not be recovered due to its retention in CNT matrix, forming a precipitate with metallic catalyst used in CNT synthesis. ${ }^{16}$ This aspect is important to consider when determning $\mathrm{F}$ by ISE, since its precipitation could lead to incorrect results.

Pyrohydrolysis is a convenient sample preparation method with complete separation between analytes and 
sample matrix. In this case, $\mathrm{F}$ is released from the sample matrix and problems related to precipitation in solution could not be expected. In addition, since higher sample amounts can be decomposed by pyrohydrolysis, better limits of detection (LOD) can be achieved. Another advantage in comparison with other methods is that analytes could be retained in diluted alkaline solutions or even in water, minimizing the occurrence of interferences in the determination step.

Pyrohydrolysis has been proposed for decomposition of many types of samples, especially for halogen determination, with good accuracy and precision. ${ }^{17-20}$ In this strategy for sample preparation, sample is heated in a quartz tube in the presence of water vapor and fluoride is hydrolyzed to the respective volatile halide (HF) that is further condensed and collected in an alkaline solution (or even water) for subsequent analysis. Because the analytes are separated from sample matrix, interferences in determination step due to the presence of some elements, such as $\mathrm{Al}, \mathrm{Fe}$ and $\mathrm{Na}$, could not be expected. ${ }^{19,20}$

In the present work, pyrohydrolysis was used for the first time for carbon nanotubes digestion for further fluoride determination by ISE. Different types of CNTs (single, SWCNT and multi-walled, MWCNT) and the concentration of absorbing solutions (water, 10 to $500 \mathrm{mmol} \mathrm{L}-1 \mathrm{NH}_{4} \mathrm{OH}$ and $\left.\left(\mathrm{NH}_{4}\right)_{2} \mathrm{CO}_{3}\right)$ were evaluated. Accuracy of the proposed method was evaluated using certified reference materials (CRMs) with similar matrix composition and also by comparison of results with those obtained by MIC. It is important to mention that using pyrohydrolysis it was possible to perform analyte determination by ISE that is a low cost technique and frequently used in many laboratories.

\section{Experimental}

Instrumentation

Samples of SWCNT and MWCNT were decomposed using a homemade pyrohydrolysis device, composed by an electrothermal heated furnace (Sanchis, Porto Alegre, RS, Brazil) with an automatic temperature control (maximum temperature of $1200{ }^{\circ} \mathrm{C}$ ), a quartz tube $(45 \mathrm{~cm}$ length and $1.2 \mathrm{~cm}$ i.d.), a water vapor generation unit, a condenser and a vessel for gaseous products retention. The pyrohydrolysis reactor was constructed using high purity quartz and it was positioned inside the electrothermal furnace. A quartz sample holder $(8 \mathrm{~cm}$ length and $1 \mathrm{~cm}$ i.d.) containing the sample was positioned inside the quartz tube. A peristaltic pump (Minipuls, Gilson, Middleton, WI, USA) equipped with a Tygon tube $(0.76 \mathrm{~mm}$ i.d. $)$ was used to transport water to a ceramic capillary $(0.5 \mathrm{~mm}$ i.d. $)$ that is placed at the inlet of the quartz tube. The outlet of ceramic capillary is heated by the furnace in order to generate the water vapor. Air was used to transport the water vapor through the quartz tube and also the pyrohydrolysis gaseous products to a condenser. Gas flow rate was set using a flow meter. The outlet of the quartz reactor was connected to a glass serpentine immersed into an ice bath to condense the vapor produced. The condensed solution was collected in a polypropylene vessel containing $10 \mathrm{~mL}$ of absorbing solution for subsequent analyte determination. Quartz wool was inserted at the outlet of pyrohydrolysis furnace to avoid that particles eventually released from sample matrix could be transported to the condenser.

For results comparison, samples of carbon nanotubes were also digested by microwave-induced combustion method. Digestion was performed in a Multiwave 3000 microwave sample preparation system (Anton Paar, Graz, Austria) with software version v1.27-Synt to run with a maximum pressure rate of 3 bar s $^{-1}$. Sample digestion was performed using 8 high-pressure quartz vessels with an internal volume of $80 \mathrm{~mL}$ (maximum pressure and temperature of 80 bar and $280{ }^{\circ} \mathrm{C}$, respectively) and a commercial quartz holder to insert the samples inside the quartz vessels.

Fluoride determination in digests obtained after pyrohydrolysis and MIC was performed using a potentiometer (781 pH/Ion meter, Metrohm, Switzerland) equipped with an ion selective electrode for fluoride (part number 6.0502.150, Metrohm) and reference electrode (Ag/AgCl, part number 6.0726.100, Metrohm). For fluoride measurement, sample solutions or standards were diluted $1+1$ using TISAB ( $\mathrm{pH} \mathrm{5.5).}{ }^{19}$ Operational conditions were set according to Dressler et al. ${ }^{19}$

\section{Samples and reagents}

Six commercial samples of SWCNT (samples A, B and C) and MWCNT (samples D, E and F) with purity higher than $95 \%$ were used. Individual carbon nanotubes length was in the range of 5 to $15 \mu \mathrm{m}$ and outside diameter from 5 to 70 $\mathrm{nm}$. Samples were dried at $60^{\circ} \mathrm{C}$ in an oven before use. For both investigated methods, CNTs were pressed as pellets (diameter of $13 \mathrm{~mm}$ ) using a hydraulic press set at 5 ton by $3 \mathrm{~min}$ (Specac, Orpington, UK). In view of the lack of certified reference material of carbon nanotubes, accuracy was evaluated using the following CRM with similar matrix composition: NIST 1632c (Trace elements in coal, Gaithersburg, MD, USA), NIST 1632b (Trace elements in coal - bituminous) and BCR 40 (Trace elements in coal, Brussels, Belgium). 
All chemicals used were of analytical grade. Solutions were prepared using water purified by a Milli-Q system (18.2 $\mathrm{M} \Omega \mathrm{cm}$, Millipore, Billerica, MA). Nitric acid $(65 \% \mathrm{v} / \mathrm{v})$ from Merck (Darmstadt, Germany) was doubly distillated in a quartz still (Millestone, Sorisole, Italy, model duoPUR 2.01E). A $10 \% \mathrm{v} / \mathrm{v}$ solution of the distilled acid was used for materials cleaning.

Absorbing solutions were prepared from concentrated ammonium hydroxide $(25 \% \mathrm{~m} / \mathrm{m}$, Merck). The concentration of $\mathrm{NH}_{4} \mathrm{OH}$ solutions investigated ranged from 10 to $500 \mathrm{mmol} \mathrm{L}^{-1}$. Ammonium carbonate solution used as absorbing solution (concentration from 10 to $500 \mathrm{mmol} \mathrm{L}^{-1}$ ) was prepared from the respective salt dissolution (Merck) in water. Water was also evaluated as absorbing solution. Fluoride stock reference solution was prepared by dissolution of sodium fluoride salt (Merck) in water. Working analytical solutions for $\mathrm{F}$ determination by ISE were prepared before use by serial dilution of stock reference solution containing $1000 \mathrm{mg} \mathrm{L}^{-1}$ of fluoride in water. A TISAB solution was prepared by dissolving $58 \mathrm{~g}$ of $\mathrm{NaCl}$ (Merck), $4 \mathrm{~g}$ of 1,2-cyclohexilenediaminetetraacetic acid (Merck), $57 \mathrm{~mL}$ of acetic acid (Merck) in $500 \mathrm{~mL}$ of water. After dissolution, the $\mathrm{pH}$ was adjusted to 5.5 with a $20 \% \mathrm{~m} / \mathrm{v}$ sodium hydroxide (Merck) solution and the volume was made up to $1000 \mathrm{~mL}$ with water. ${ }^{19}$ Ammonium vanadate (Merck) was heated during $4 \mathrm{~h}$ in a platinum crucible at $550{ }^{\circ} \mathrm{C}$ to produce $\mathrm{V}_{2} \mathrm{O}_{5}$ that was used as auxiliary in pyrohydrolysis.

\section{Application of pyrohydrolysis and MIC for carbon nanotubes} digestion

For pyrohydrolysis method, SWCNT and MWCNT samples, pressed as pellets, were transferred to the quartz holder of pyrohydrolysis system. Then, the quartz holder containing the sample was positioned inside the quartz tube. The electrical furnace was heated up to $950{ }^{\circ} \mathrm{C}$ and water was pumped through a heated ceramic capillary at a flow rate of $0.5 \mathrm{~mL} \mathrm{~min}^{-1}$ generating water vapor inside the quartz tube. The flow rate of carrier gas (air) was set at $200 \mathrm{~mL} \mathrm{~min}^{-1}$. It was used to transfer the gaseous products to the collector vessel containing $10 \mathrm{~mL}$ of absorbing solution. Tests were also performed by transferring the gaseous products directly to an empty collector vessel (without absorbing solution). After the reaction time $(10 \mathrm{~min})$, the resulting solution (condensed water vapor) was diluted with water to $25 \mathrm{~mL}$. After each run, the pyrohydrolysis quartz holder was soaked in concentrated $\mathrm{HNO}_{3}$ for 10 min and further rinsed with water. Between different samples, nitric acid was transferred to the sample holder and submitted to a heating step at $950{ }^{\circ} \mathrm{C}$ for $10 \mathrm{~min}$ for pyrohydrolysis apparatus cleaning.
For MIC procedure, a pellet of $500 \mathrm{mg}$ of CNT was positioned in the quartz holder with a disc of filter paper wet with $50 \mu \mathrm{L}$ of $6 \mathrm{~mol} \mathrm{~L}^{-1}$ ammonium nitrate solution. ${ }^{16}$ The quartz holder was placed inside the quartz vessel containing $6 \mathrm{~mL}$ of $100 \mathrm{mmol} \mathrm{L}^{-1} \mathrm{NH}_{4} \mathrm{OH}$. Vessels were closed and pressurized with oxygen at $20 \mathrm{bar}$ for $1 \mathrm{~min}$. The rotor with vessels was placed inside the microwave cavity and the microwave heating program was started. Microwave heating program used for MIC was $1400 \mathrm{~W}$ for $5 \mathrm{~min}$ and $0 \mathrm{~W}$ for $20 \mathrm{~min}$ (cooling step). After the end of the program, the pressure of each vessel was released and the resulting solutions were transferred to polypropylene vessels and diluted with water to $30 \mathrm{~mL}$ for further analysis. ${ }^{16}$ After each run, holders and vessels were washed for 10 min with concentrated $\mathrm{HNO}_{3}$ under microwave-assisted heating $(1400 \mathrm{~W})$.

\section{Results and Discussion}

\section{Carbon nanotubes digestion: preliminary tests}

Microwave-induced combustion has been used for different samples presenting high efficiency of digestion and leading to solutions suitable for further halogen determination..$^{21-24}$ In the present work, MIC was used for CNT digestion (samples A to F) for further fluoride determination and results were used as reference for the optimization of the proposed pyrohydrolysis procedure. In this sense, about $500 \mathrm{mg}$ of CNTs were digested using 20 bar of oxygen and $100 \mathrm{mmol} \mathrm{L}^{-1} \mathrm{NH}_{4} \mathrm{OH}$ as absorbing solution. These conditions were selected according to a previous work. ${ }^{16}$ The MIC method was used for total digestion of all CNT samples and F was determined by ISE. Fluorine concentration of CNT samples $\mathrm{A}, \mathrm{B}, \mathrm{D}, \mathrm{E}$ and $\mathrm{F}$ were $77.1 \pm 1.6,23.8 \pm 0.9,44.5 \pm 1.8$, $13.2 \pm 0.4$ and $4.35 \pm 0.16 \mu \mathrm{g} \mathrm{g}^{-1}$, respectively. For CNT sample $\mathrm{C}$ the concentration of fluoride was lower than the LOD obtained by ISE $\left(1.5 \mu \mathrm{g} \mathrm{g}^{-1}\right.$, calculated according to the literature ${ }^{25}$ ). These values were used as reference for further optimization of pyrohydrolysis procedure. It is important to notice that using MIC, blank levels for fluoride were always negligible. In addition, the relative standard deviation (RSD) was always lower than 5\%.

Optimization of pyrohydrolysis system for CNTs digestion and further fluoride determination

For optimization of pyrohydrolysis system, one sample of CNT was arbitrary selected (sample A) and results were evaluated based on the value obtained after MIC digestion $\left(77.1 \pm 1.6 \mu \mathrm{g} \mathrm{g}^{-1}\right)$. The type of absorbing solution (water, $\left(\mathrm{NH}_{4}\right)_{2} \mathrm{CO}_{3}$ or $\left.\mathrm{NH}_{4} \mathrm{OH}\right)$ and the maximum sample mass 
that could be digested by pyrohydrolysis were investigated.

The following solutions were investigated as absorbing solution (the volume of solution used was kept at $10 \mathrm{~mL}$ ): water, $\left(\mathrm{NH}_{4}\right)_{2} \mathrm{CO}_{3}$ or $\mathrm{NH}_{4} \mathrm{OH}$ in different concentrations for alkaline media $\left(10,25,50,100,250\right.$ and $\left.500 \mathrm{mmol} \mathrm{L}^{-1}\right)$. The temperature and reaction time were chosen according to previous works $\left(950{ }^{\circ} \mathrm{C}\right.$ and $10 \mathrm{~min}$, respectively) for $\mathrm{F}$ determination in fossil fuels, geological and biological samples. ${ }^{19,26}$ In addition, a study was performed without using the absorbing solution in the collector vessel. In this case, water vapor used for pyrohydrolysis was condensed and collected directly in a vessel without solution. After finishing the reaction, $\mathrm{F}$ determination was performed in digests by ISE and results are shown in Figure 1.

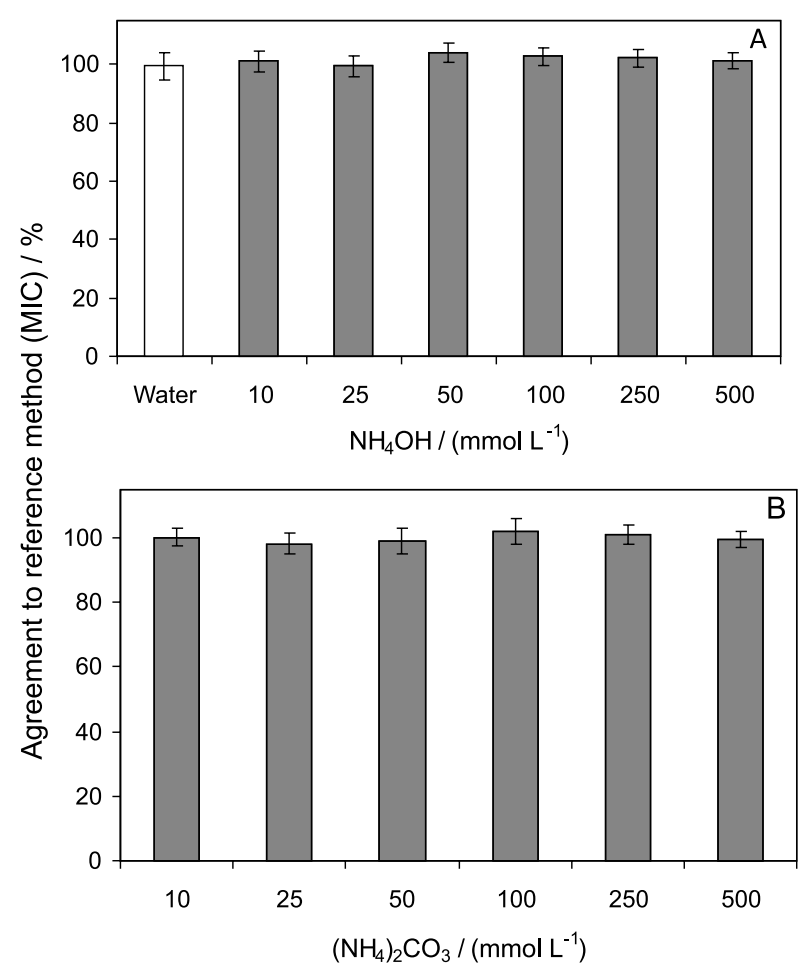

Figure 1. Agreement obtained for F after pyrohydrolysis of CNT using (A) water (vapor condensed during pyrohydrolysis reaction) and ammonium hydroxide and (B) ammonium carbonate as absorbing solutions (results were compared with values obtained after MIC digestion). Error bars correspond to standard deviation $(\mathrm{n}=3)$. Pyrohydrolysis conditions: $500 \mathrm{mg}$ of sample, temperature of $950{ }^{\circ} \mathrm{C}, 10 \mathrm{~min}$ of reaction and air flow rate of $200 \mathrm{~mL} \mathrm{~min}^{-1}$.

The agreement with the reference value (obtained after MIC digestion) was better than $95 \%$ for all investigated concentrations of $\left(\mathrm{NH}_{4}\right)_{2} \mathrm{CO}_{3}$ and $\mathrm{NH}_{4} \mathrm{OH}$. However, blank values were slightly higher when $\left(\mathrm{NH}_{4}\right)_{2} \mathrm{CO}_{3}$ solutions were used. Even using only water, quantitative result was obtained (agreement to reference value of 97\%). This fact could be explained due to the high solubility of HF in water. In this case, the use of an alkaline solution was considered as not necessary and a RSD lower than 5\% $(n=3)$ was achieved. This behavior was also observed by other authors for different types of samples (geological, biological and fossil fuels) in which the analyte was retained in the condensate obtained after pyrohydrolysis. ${ }^{19,20}$ In this case, about $10 \mathrm{~mL}$ of water vapor was collected after the temperature of $950{ }^{\circ} \mathrm{C}$ has been reached. This is an important aspect regarding to the use of pyrohydrolysis for CNT and further $\mathrm{F}$ determination since the analyte absorption could be performed in water minimizing contamination and reducing blank values, consequently, better LODs can be obtained. Therefore, for subsequent studies, no absorbing solution was used and $\mathrm{F}$ was determined in the condensed water vapor after pyrohydrolysis reaction.

In the present work, an auxiliary agent $\left(\mathrm{V}_{2} \mathrm{O}_{5}\right)$ for CNT sample preparation by pyrohydrolysis was not used since quantitative analyte recoveries were obtained (in comparison with the results obtained by MIC). This is in agreement with other works where the auxiliary agent was not necessary for $F$ release and quantitative recoveries were obtained for different matrices, including coal, coal fly ash and fossil fuels. ${ }^{19,20,26}$ This shows that pyrohydrolysis is a robust method for decomposition of these materials, in spite of the great difference of the matrix. In coals, the mineral content can reach up to $50 \%$ while the matrix of CNT is predominantly carbon (CNT could be contaminated with $\mathrm{La}, \mathrm{Ni}, \mathrm{Fe}, \mathrm{Co}$ and $\mathrm{Y}$, but the concentration is normally lower than 5\%). It is well documented that $\mathrm{F}$ is predominantly associated with minerals. ${ }^{27}$ Therefore, it was expected that the conditions of pyrohydrolyis to release F from these materials would be affected. However, this behavior was not observed in this work.

The maximum mass of sample that could be used for pyrohydrolysis method using the proposed system was evaluated. Since it was not necessary to use an auxiliary agent, it is expected that higher sample masses could be used that is an important aspect to improve LODs. In this sense, experiments were performed using 100 to $1000 \mathrm{mg}$ of sample. The use of higher amounts of samples was limited by the dimensions of quartz holder and reactor quartz tube. According to the results, good agreement with reference values (MIC digestion and F determination by ISE) were obtained using sample masses up to $1000 \mathrm{mg}$. This is an important aspect concerning sample preparation in order to achieve low LODs and to perform analyte determination at trace levels.

Fluoride determination in carbon nanotubes by ISE after pyrohydrolysis

After optimization of pyrohydrolysis parameters, single and multi-walled CNT samples were prepared as pellets 
and fluoride determination was performed by ISE. Fluoride measurements were performed by mixing equal volumes of digest obtained after pyrohydrolysis and TISAB. This procedure was also performed for the standard solutions used in the calibration step. It is important to point out that none interferences were observed during fluoride determination by ISE probably due to analyte separation from sample matrix using pyrohydrolysis method. Results are shown in Table 1.

Table 1. Fluoride concentration in CNT (samples A, B and C are SWCNT and samples D, E and F are MWCNT) and CRMs determined by ISE after pyrohydrolysis and MIC (mean \pm standard deviation, $\mathrm{n}=3$ )

\begin{tabular}{lccc}
\hline \multirow{2}{*}{ Sample } & Certified values $/$ & \multicolumn{2}{c}{ Fluoride / $\left(\mu \mathrm{g} \mathrm{g}^{-1}\right)$} \\
\cline { 3 - 4 }$\left(\mu \mathrm{g} \mathrm{g}^{-1}\right)$ & - & MIC & Pyrohydrolysis \\
\hline $\mathrm{A}$ & - & $27.1 \pm 1.6$ & $76.7 \pm 1.5$ \\
$\mathrm{~B}$ & - & $<3.0$ & $<1.5$ \\
$\mathrm{C}$ & - & $44.5 \pm 1.8$ & $44.8 \pm 1.3$ \\
$\mathrm{D}$ & - & $13.2 \pm 0.4$ & $12.9 \pm 0.3$ \\
$\mathrm{E}$ & - & $4.35 \pm 0.16$ & $4.31 \pm 0.12$ \\
F & $72.7 \pm 6.8$ & $74.2 \pm 4.9$ & $74.3 \pm 4.2$ \\
NIST 1632c & $41.7 \pm 3.2$ & $41.4 \pm 3.5$ & $41.5 \pm 3.6$ \\
NIST 1632b & $111.4 \pm 8.5$ & $110 \pm 8.8$ & $109 \pm 8.7$ \\
BCR 40 & & &
\end{tabular}

The concentration of fluoride in CNTs analyzed after pyrohydrolysis varied from 4.3 to $78 \mu \mathrm{g} \mathrm{g}^{-1}$ and for sample $\mathrm{C}$, fluoride concentration was lower than LOD obtained by ISE. It is important to mention that no differences were observed in the digestion procedure for SWCNT or MWCNT (pyrohydrolysis was efficient for digestion of both CNT types). In addition, an agremeent better than 95\% was obtained comparing the results for fluoride in digests obtained after MIC and pyrohydrolysis. For acccuracy evaluation, CRMs of similar matrix composition (coal) were also used since no CRM of carbon nanotubes was available. In this sense, NIST 1632c, NIST 1632b and BCR 40 (coal samples) were digested by pyrohydrolysis under optimized conditions and accuracy was better than 95\% (Table 1). Therefore, pyrohydrolysis could be a method of choice for CNT digestion for subsequent $\mathrm{F}$ determination by ISE, presenting good accuracy, high efficency of digestion and low LODs.

\section{Conclusions}

The proposed pyrohydrolysis method was suitable for SWCNT and MWCNT digestion for further fluoride determination by ISE. The pyrohydrolysis system is relatively easy to be built in laboratories and presents low cost. The recovery of fluoride was quantitative by condensation of water vapour containing the analyte from pyrohydrolysis reaction or its absorption by $\mathrm{NH}_{4} \mathrm{OH}$ or $\left(\mathrm{NH}_{4}\right)_{2} \mathrm{CO}_{3}$ solutions. It was not necessary to use an auxiliary agent $\left(\mathrm{V}_{2} \mathrm{O}_{5}\right)$ for this type of sample. These characteristics are important concerning green chemistry recommendations.

Results obtained for CRM using pyrohydrolysis under optimized conditions were in agreement with certified values and with values obtained after MIC digestion. The proposed pyrohydrolysis system allows the preparation of high sample masses $(1 \mathrm{~g})$, combining safety, relatively high sample throughput, matrix separation and low cost. Therefore, pyrohydrolysis can be recommended for F determination by ISE in CNT complying with the requirements for quality control of this type of material.

\section{Acknowledgments}

The authors are grateful to Coordenação de Aperfeiçoamento de Pessoal de Nível Superior (CAPES) and Conselho Nacional de Desenvolvimento Científico e Tecnológico (CNPq) for supporting this study.

\section{References}

1. Tasis, D.; Tagmatarchis, N.; Bianco, A.; Prato, M.; Chem. Rev. 2006, 106, 1105.

2. Merkoci, A.; Microchim. Acta 2006, 152, 157.

3. Janegitz, B. C.; Figueiredo Filho, L. C. S.; Marcolino-Junior, L. H.; Souza, S. P. N.; Pereira Filho, E. R.; Fatibello Filho, O.; J. Electroanal. Chem. 2011, 660, 209.

4. Janegitz, B. C.; Pauliukaite, R.; Ghica, M. E.; Brett, C. M. A.; Fatibello Filho, O.; Sens. Actuators, B 2011, 158, 411.

5. Hsieh, T. H.; Kinloch, A. J.; Taylor, A. C.; Kinloch, I. A.; J. Mater. Sci. 2011, 46, 7525.

6. Trojanowicz, M.; TrAC, Trends Anal. Chem. 2006, 25, 480.

7. Unger, E.; Graham, A.; Kreupl, F.; Liebau, M.; Hoenlein, W.; Curr. Appl. Phys. 2002, 2, 107.

8. Khabashesku, V. N.; Billups, W. E.; Margrave, J. L.; Acc. Chem. Res. 2002, 35, 1087.

9. Ly, S. Y.; Talanta 2008, 74, 1635.

10. Ge, C.; Lao, F.; Li, W.; Li, Y.; Chen, C.; Qiu, Y.; Mao, X.; Li, B.; Chai, Z.; Zhao, Y.; Anal. Chem. 2008, 80, 9426.

11. Mortari, S. R.; Cocco, C. R.; Bartz, F. R.; Dresssler, V. L.; Flores, E. M. M.; Anal. Chem. 2010, 82, 4298.

12. Wepasnick, K. A.; Smith, B. A.; Bitter, J. L.; Fairbrother, D. H.; Anal. Bioanal. Chem. 2010, 396, 1003.

13. Mello, P. A.; Rodrigues, L. F.; Nunes, M. A. G.; Mattos, J. C. P.; Mueller, E. I.; Dressler, V. L.; Flores, E. M. M.; J. Braz. Chem. Soc. 2011, 22, 1040.

14. Zeisler, R.; Paul, R. L.; Spatz, R. O.; Yu, L. L.; Mann, J. L.; Kelly, W. R.; Lang, B. E.; Leigh, S. D.; Fagan, J.; Anal. Bioanal. Chem. 2011, 399, 509. 
15. Pereira, J. S. F.; Mello, P. A.; Moraes, D. P.; Duarte, F. A.; Dressler, V. L.; Knapp, G.; Flores, E. M. M.; Spectrochim. Acta, Part B 2009, 64, 554.

16. Pereira, J. S. F.; Antes, F. G.; Diehl, L. O.; Knorr, C. L.; Mortari, S. R.; Dressler, V. L.; Flores, E. M. M.; J. Anal. At. Spectrom. 2010, 25, 1268.

17. Antes, F. G.; Duarte, F. A.; Paniz, J. N. G.; Santos, M. F. P.; Guimarães, R. C. L.; Flores, E. M. M.; Dressler, V. L.; At. Spectrosc. 2008, 29, 157.

18. Antes, F. G.; Santos, M. F. P.; Guimarães, R. C. L.; Gottfried Paniz, J. N.; Moraes Flores, E. M.; Dressler, V. L.; Anal. Methods 2011, 3, 288.

19. Dressler, V. L.; Pozebon, D.; Flores, E. L. M.; Paniz, J. N. G.; Flores, E. M. M.; Anal. Chim. Acta 2002, 466, 117.

20. Dressler, V. L.; Pozebon, D.; Flores, E. L. M.; Paniz, J. N. G.; Flores, E. M. M.; J. Braz. Chem. Soc. 2003, 14, 334.

21. Moraes, D. P.; Pereira, J. S. F.; Diehl, L. O.; Mesko, M. F.; Dressler, V. L.; Paniz, J. N. G.; Knapp, G.; Flores, E. M. M.; Anal. Bioanal. Chem. 2010, 397, 563.

22. Pereira, J. S. F.; Knorr, C. L.; Pereira, L. S. F.; Moraes, D. P.; Paniz, J. N. G.; Flores, E. M. M.; Knapp, G.; J. Anal. At. Spectrom. 2011, 26, 1849.
23. Pereira, J. S. F.; Moraes, D. P.; Antes, F. G.; Diehl, L. O.; Santos, M. F. P.; Guimarães, R. C. L.; Fonseca, T. C. O.; Dressler, V. L.; Flores, E. M. M.; Microchem. J. 2010, 96, 4.

24. Pereira, J. S. F.; Moreira, C. M.; Albers, C. N.; Jacobsen, O. S.; Flores, E. M. M.; Chemosphere 2011, 83, 281.

25. Buck, R. P.; Lindner, E.; Pure Appl. Chem. 1994, 66, 2527.

26. Antes, F. G.; Duarte, F. A.; Flores, E. L. M.; Paniz, J. N. G.; Flores, E. M. M.; Dressler, V. L.; Quim. Nova 2010, 33, 1130.

27. Finkelman, R. B. In: Environmental Aspects of Trace Elements in Coal. Swaine, D. J.; Goodarzi, F. (eds.). Kluwer Academic Publishers: Amsterdam, 1995, ch. 3.

Submitted: November 21, 2011

Published online: April 26, 2012 